\title{
Risk of breast cancer in women who attend the NHS breast screening programme: cohort study
}

\author{
Anthony G Threlfall, Ciaran B J Woodman
}

Centre for Cancer Epidemiology, University of Manchester, Withington, Manchester M20 4QL

Anthony G Threlfall research associate Ciaran B J Woodman professor of cancer epidemiology and public health

Correspondence to: C B J Woodman Ciaran.woodman@ cce.man.ac.uk
Not all women invited to participate in the NHS breast screening programme will do so; those who do not may differ in their risk of breast cancer from those who do. This "self selection" for screening can result in women at either high or low risk being overrepresented in those screened. A screening programme in which those who attend have a high risk of breast cancer is likely to detect more cancers and be of more benefit to the women screened than a programme with a similar participation rate but no self selection of women at high risk. In the Health Insurance Plan of Greater New York (HIP) and Stockholm trials, the incidence of breast cancer in non-attenders was lower than in the control group but no difference was observed in the Edinburgh trial. ${ }^{12}$ We report, for the first time, the incidence of breast cancer in women who declined to participate in the NHS breast screening programme.

\section{Methods and results}

A total of 44430 women born between 1 January 1926 and 31 December 1940 were first invited for screening by the Manchester and Wigan screening programmes between 1 January 1989 and 30 September 1990, and between 1 January 1989 and 30 June 1990, respectively. The records of these women were linked with those held by the NHS central register to ensure that only women living in the catchment area of the cancer registry in the North Western region were included in the analysis. A woman was removed from the analysis when she had died or left the catchment area before her first scheduled screen, when her registration with a general practitioner had been cancelled and her whereabouts were unknown, or when no match was found. Women were withdrawn from follow up when they died or left the catchment area; follow up of the remaining women was censored at 31 December 1998. All primary breast cancers occurring in this population were identified from records held by the cancer registry. The number of cancers expected to occur during follow up in non-attenders was calculated using age specific incidence rates for Manchester and Wigan in 1987, the last complete year before the introduction of the screening programme for which incidence rates were available.

The final study population included 40939 women: $33706(82.3 \%)$ attended on at least one occasion, and 7233 (17.7\%) never attended. The number of non-attenders diagnosed with breast cancer during 69098 person years of follow up was 121; this is significantly less than the 147.2 cancers expected $\left(\chi^{2}=4.66, \mathrm{df}=1, \mathrm{P}<0.05\right)$ and yields an observed to expected incidence ratio of $0.82(95 \%$ confidence interval 0.68 to 0.98 ). The expected number is almost certainly an underestimate because the incidence of breast cancer had been increasing steadily before the introduction of the screening programme. Therefore, an age-period model was used to predict the expected number of cancers in women aged 50-64 years in 1994, the midpoint of the study period, in the absence of screening. ${ }^{34}$ Use of these estimates suggests an observed to expected incidence ratio of 0.74 ( 0.59 to 0.91).

\section{Comment}

The risk of breast cancer in non-attenders is lower than that in the population targeted for screening. Therefore, the risk in those who attend must be higher: this might occur, for example, if women with a family history of breast cancer were more likely to attend. Our findings suggest that, with current levels of compliance, the proportion of breast cancers potentially detectable by screening is higher than expected when cancer detection targets were set. This may partially explain the apparent paradox that high interval cancer rates have been reported in the NHS breast screening programme despite many screening centres achieving their detection targets. When these targets were set, no data were available on the incidence of breast cancer in non-attenders, and a possible selection bias was discounted. ${ }^{5}$ These targets now need to be revisited.

We thank the clinical directors of the Manchester and Wigan breast screening programmes for the provision of data and Colin Jones and Brad Donnelly for computer support.

Contributors: AGT and CBJW conceived the idea, designed the study, and wrote the paper. AGT compiled the data, undertook the analysis, and is guarantor of the work. David Mannion from the North Western region's breast screening quality assurance programme helped collect data from the screening units.

Funding: AGT is funded by the NHS North West Executive's research and development training Fellowship programme. Competing interests: None declared.

1 Richardson A, Wells J. Breast cancer screening: the effect of self selection for screening on comparisons of randomised controlled trials. J Med Screening 1997;4:16-8.

2 Frisell J, Lidbrink E, Hellström L, Rutquist L-E. Followup after 11 yearsupdate of mortality results in the Stockholm mammographic screening trial. Breast Cancer Res Treatment 1997;45:263-70.

3 Prior P, Woodman CBJ, Wilson S, Threlfall AG. Reliability of underlying incidence rates for estimating the effect and efficiency of screening for breast cancer. J Med Screening 1996;3:119-22.

4 Quinn M, Allen E. Changes in incidence of and mortality from breast cancer in England and Wales since introduction of screening. BMJ 1995;311:1391-5.

5 Moss S, Blanks R. Calculating appropriate target cancer detection rates and expected interval cancer rates for the UK NHS breast screening programme. J Epidemiol Community Health 1998;52:111-5. (Accepted 19 March 2001)

\section{Endpiece}

\section{Friendship}

Friendship is a mysterious power: you show your friend your weakness, and somehow you are both the stronger.

Martin Amis, Experience, London: Jonathan Cape, 2000 